\title{
The Classification of Melancholia in Mid-Nineteenth-Century British Medicine
}

The symptoms of melancholia are so well pronounced when present, and hence so readily recognized, that they do not require to be very minutely described. J.C. Bucknill and Daniel Hack Tuke (1858)

In 1863 William Sankey, medical superintendent at Hanwell Asylum in Sussex, offered a survey of current perspectives on melancholia in European medicine. ${ }^{l}$ One of the first things he noted when comparing works by British, German, and French physicians was the lack of agreement over the nosological status of this disease category:

The foremost question with respect to melancholia is its position in nosology. Some of the authors enumerated ${ }^{2}$ ignore its existence as a distinct form of insanity, others retain it as one of the chief divisions of their classification of mental maladies. Now, taking a broad, or what may be called a distant view of the whole, nothing appears more marked or distinct than melancholia from other kinds of insanity. ${ }^{3}$

Sankey's 'distant view' was to become typical of his British cohort in the last decades of the nineteenth century. However, as Sankey's survey indicated, during the first half of the nineteenth century British and European medical literature on melancholia was characterised by divergence rather than coherence. Some physicians, most notably J.C. Prichard, rejected the validity and usefulness of the diagnosis altogether, seeking to replace

(C) The Author(s) 2021

Å Jansson, From Melancholia to Depression, Mental Health in Historical Perspective, https://doi.org/10.1007/978-3-030-54802-5_3 
it with other diagnostic terms or subsume it under broader categories. At the same time, a reconceptualisation of melancholia began in the early 1840 s, a process which would eventually produce a far more standardised and coherent version of this category than had previously existed. This process had its origins in experimental physiology, and emerged out of an ongoing conceptual and terminological shift in the philosophy and science of emotion.

This chapter maps the shifting nosological status of melancholia in mid-century British medical literature, beginning in the 1830s and ending with Sankey's review of contemporary literature on the topic. At the turn of the century, medical writers had begun to argue that the 'passions' played a central role in milder forms of insanity. ${ }^{4}$ This idea, emerging before psychiatry itself, proved popular, flexible, and durable. It was foundational to the modern medical concept of disordered mood, and has persisted in some form or another until the present. The twenty-firstcentury reader must, however, note that to suggest, as Enlightenment physician Phillipe Pinel did, that strong passions can be a cause or symptom of madness, is something quite different from suggesting that emotion is a physiological process prone to disorder and disease. ${ }^{5}$ Moreover, it is equally important to note that both these explanations are quite far apart from the twenty-first-century neurochemical model for disorders of mood.

The biomedical melancholia that emerged at mid-century had two important conceptual features, one external and one internal. Externally, it was perceived as a form of mental disease in which emotion was the main, or only, faculty affected, and as such it could present without delusion of thought. An editorial in the Journal of Psychological Medicine in 1850 posing the question 'Are delusions always present in melancholia?' is illustrative of this approach. The answer offered by the author ${ }^{6}$ was decisive: 'We doubt it. Cases of intense melancholia have come under our notice and care, in which we could not trace the faintest semblance of delusion of any kind' 7 Internally, melancholia was conceptualised in physiological (functional) rather than anatomical (structural) language as a form of insanity that rarely left visible marks on the brain. In a speech delivered at Hanwell Asylum the same year as the article quoted above, John Hitchman forcefully argued that '[i]n every case of insanity, there is irritation, or disease of the grey matter in the encephalon'. ${ }^{8}$ He suggested that, while visible lesions may not always be discovered, indeed may not occur at all, mental disease nonetheless always entailed a disorder of brain 
function. He cited in support of this argument the case of a forty-sixyear-old woman diagnosed with melancholia. Her subsequent death was deemed the result of liver failure unrelated to her mental disturbance; the post-mortem examination revealed no abnormalities of brain tissue. This failure to find lesions on her brain was, however, used as a defence of the cerebral theory rather than to rebuke it. The case was presented as evidence of melancholia as a disease of the physiology of emotion rather than an illness causing visible and lasting structural damage to the brain. ${ }^{9}$

As discussed in the Introduction, in European medical literature the term melancholia had traditionally been deployed to describe various manifestations of delusional madness characterised by sadness, grief, and despair. Prior to the modern period there was consistently both tension and harmony between medical and lay views of melancholia as madness and melancholy as feeling or temperament. Moreover, in medieval and early modern literature on melancholia and melancholy distinctions were not always made between medical and non-medical descriptions, the most obvious and famous example being the mammoth three-volume ode to melancholy written by sixteenth-century clergyman Robert Burton. While lay and medical perceptions of melancholia and melancholy continued to interact to some extent in the nineteenth century, ${ }^{10}$ the two realms grew increasingly separate. This is particularly evident on the pages of asylum casebooks, where patients' expressed religious guilt and fear of divine punishment were generally interpreted and noted down by medical officers as 'religious delusions'. In Victorian Britain, the disease category melancholia came within the purview of psychological medicine (later psychiatry). As such it became a classifiable, diagnosable mental disease with a specific set of symptoms, and often with an expected course of progression. As a disease concept reinvented by physicians wedded to a biological, and specifically physiological, view of health and illness, melancholia was fashioned with a plausible biomedical model that explained in scientific terms how the disease arose. The previous chapter showed how this model was created through an appropriation of language and concepts from experimental physiology, an event that constituted emotion as an automated physiological process. However, the status of melancholia as a distinct mental disease was uncertain in the first half of the century. In part due to the influence of French alienism, particularly the nosological approach of Parisian physician J.E.D. Esquirol, attempts were made to do away with the centuries-old traditional category melancholia. Newer concepts such as 'monomania' and 'moral insanity' 
threatened to eclipse or even erase melancholia as a diagnostic category in British psychological medicine. However, by the end of the century, melancholia was not only one of the most common forms of mental disease diagnosed in British asylums, it was also one of the most written about in medical literature. Moreover, descriptions of this disease, both in medical texts and asylum casebooks, were remarkably standardised for an age when psychiatry was still in its infancy and no formal standard nosology existed in Britain or elsewhere. This and subsequent chapters constitute an attempt to map how and why this happened.

To tell this story chronologically poses some difficulties, as the reconceptualisation of melancholia was not a linear development. In 1845, influential German psychiatrist Wilhelm Griesinger used his theory of psychological reflexion, which closely resembled Laycock's, to explain the internal aetiology of melancholia in the first edition of his textbook on psychiatry. However, his work was not translated into English until two decades later, and then it was a revised and expanded second edition that finally reached an English readership. At the same time, British writers on mental disease began to appropriate physiological research from the late 1840s, drawing on the works of people like Laycock, Carpenter and Billing. This was, however, a patchy process; biomedical models for melancholia similar to that offered by Griesinger began to gain a foothold in British medical literature in the early 1850s, but many physicians equally continued to favour a more traditional view of mental disease. Griesinger's work and its impact on British theories of mental disease will be considered in detail in Chapter 4 . This chapter will begin, however, with the state of British nosology in the first half of the nineteenth century, prior to any significant uptake of physiology into literature on insanity. This is illustrated chiefly by the work of British physician J.C. Prichard, whose major textbook of insanity published in 1835 was largely based on the teachings of Esquirol. The chapter continues into the $1840 \mathrm{~s}$ and $50 \mathrm{~s}$, when British asylum physicians were increasingly embracing models of mental disease based on physiological concepts. Around mid-century, nosological approaches varied, sometimes greatly, yet melancholia was rapidly taking shape as a distinct and easily identifiable disease category, prompting Sankey's conclusion above. 


\section{Melancholia, Monomania and Moral Insanity}

When Bristol physician James Cowles Prichard's monograph A Treatise on Insanity was first published in 1835 it became part of a relatively sparse catalogue of home-grown British works on mental disorders. While a growing number of public and private lunatic asylums existed around the country in the mid-1830s, standard national guidelines on the management of these were still a decade away. There was as yet no professional association or journal in Britain (unlike on the continent) and universities offered no formal training in what was to become 'psychological medicine' (and later psychiatry). All of this would, however, soon begin to change. Indeed, Prichard himself went on to become one of the first national Lunacy Commissioners in 1845 , just a few years before his death. However, at the time when he produced his main work on insanity the landscape of British psychological medicine was still uneven and comparatively barren. Prichard had travelled to Paris and trained under the famous alienist Esquirol, and had become so impressed with the Parisian physician that not only did he attempt to adapt the latter's nosology for a British audience, he even dedicated $A$ Treatise on Insanity to his mentor. ${ }^{11}$

Despite a relative scarcity of literature compared to subsequent decades, Prichard's monograph was not the only Anglo-Saxon text on mental disorders available to British physicians in the 1830s. This was a time when the Tuke family's advocacy for moral management of lunatics was gaining ground across the country, perhaps most passionately supported by Prichard's contemporary John Conolly, whose work is considered below. Prichard's classification of insanity, and his approach to melancholia in particular, offers a fitting starting point for the discussion that will unfold in this chapter as it represents a particular early nineteenth-century approach to the classification and diagnosis of mental disease, one which marked itself quite clearly both from traditional medical writings on madness, and the physiologically inspired models that would follow. It was also the by subsequent generations of medical psychologists most read and cited early century British publication on insanity.

While historians have primarily attributed Prichard's place in psychiatry's hall of fame to his supposed invention of the term 'moral insanity', ${ }^{12}$ he was also much preoccupied with Esquirol's versatile category 'monomania'. Following Esquirol, he attempted to subsume melancholia under this umbrella category. In doing so, he also classified 
melancholia as a form of 'partial insanity', a type of madness in which the intellect was only compromised in regards to one particular aspect or idea. This, indeed, was arguably Prichard's more significant contribution to the early creation of diagnostic categories in psychiatry. When the Metropolitan Commissioners in Lunacy (a precursor to the nationwide Lunacy Commission) adopted a formal nosology in the 1840s this included the umbrella category partial insanity under which melancholia was listed alongside monomania and moral insanity. Prichard, however, used partial insanity interchangeably with monomania, and distinguished it from moral insanity. The latter he defined as 'a morbid perversion of the natural feelings, affections, inclinations, temper, habits, moral dispositions, and natural impulses, without any remarkable disorder or defect of the intellect or knowing and reasoning faculties, and particularly without insane delusion or hallucination'. ${ }^{13}$ Conversely, monomania (or partial insanity) did involve some measure of intellectual disorder, pertaining to 'one subject, and involving one train of ideas'. The central premise of Prichard's nosological approach was significant: that one could be mad without being fully delusional, an idea that had been gaining ground in medical circles across Western Europe at least since the turn of the nineteenth century.

In addition to Esquirol, Prichard found his inspiration among other European writers, whose work he subjected to critical analysis. He paid a great deal of attention to the early German school of psychiatry, particularly the work of Johann Christian Heinroth, whose view of insanity reflected a Romanticist philosophical worldview. Early nineteenth-century German literature on madness produced in this vein tended to emphasise the importance of the passions (and the soul) in mental disease (Heinroth himself referred to madness as Seelenstörungen-disturbances of the soul). ${ }^{14}$ However, it was different from the French school in that the latter showed greater interest in the potentially physical basis of insanity; anatomical investigations and particularly psychiatric post-mortems were commonplace in the Parisian hospitals. ${ }^{15}$ Prichard attempted to incorporate some of the recent findings of such empirical research, taking stock of the various European writers who had tried to locate madness in brain tissue. His discussion did not, however, move beyond anatomy to take in any aspects of the research emerging at the time in the area of experimental physiology. For the most part, Prichard's approach largely followed that of Esquirol, stating that abnormalities found in the brain 
tissue of dead asylum patients suggested that insanity was a morbid condition affecting the brain. However, he withheld judgement on whether 'disorders in the affections and feelings' were purely or chiefly cerebral, suggesting that 'however probably it may be thought by some persons that the passions and propensities are seated in the brain, or that modifications which the mind undergoes with respect to these phenomena are connected with instrumental changes in the brain, the fact has never been proved'. ${ }^{16}$

Prichard was primarily concerned with the description of symptoms and the classification of these into correct categories. He suggested of melancholia that it was an outdated term that failed to accurately convey the type of illness it was usually deployed to describe, since 'the illusions which possess the mind are not constantly, in individuals partially insane, indicative of grief and melancholy'. ${ }^{17}$ Thus, he concluded that 'Melancholia seemed to be an improper designation for cases of this kind; and the term Monomania, which was happily suggested by M. Esquirol, has been universally adopted in its place'. ${ }^{18}$ Prichard was somewhat optimistic in his assessment of the impact of his mentor's nosology; monomania never completely replaced melancholia, but it was taken up by other British writers and became for a while a relatively widely used category in psychological medicine. Esquirol had suggested lypemanie ('sadness mania') to denote a melancholic subtype of monomania, but Prichard did not perceive such a specific label to be necessary.

Moral insanity featured at least peripherally as a diagnosis into the second half of the century. Yet, as will be seen in Chapter 5, the nosology favoured by the Lunacy Commission gave primacy to the more well-established categories melancholia, mania, dementia, and general paralysis. Asylum physicians were encouraged to use preprinted forms produced by the Commission to record diagnoses and symptoms, an act that facilitated a gradual standardisation of diagnostics within the significant portion of British psychological medicine that was tied to the asylum. Moreover, the nineteenth-century meaning of 'moral' was ambiguous. While Prichard used the term to mean 'psychological' in the wider sense, ${ }^{19}$ conceptualising moral insanity as a form of partial affective mental disease, others used the word specifically to denote insanity that manifested in immoral feelings, thoughts, and actions. James Davey suggested that 'several cases given by Dr. Prichard to illustrate what he conceived to be moral insanity, were instances of everyday mania in which the intellectual faculties had escaped the ravages of the disease affecting 
the emotional qualities of the mind'. Rather, Davey argued, the diagnosis of moral insanity should be confined to cases where a 'well marked predisposition to the indulgence of the lower feelings and animal desires is manifested'. ${ }^{20}$ He deferred to Thomas Mayo's Elements of Pathology of the Human Mind (1838) to suggest that moral insanity proper involved an element of 'brutality'. ${ }^{21}$ According to Mayo, brutality arose from a 'defect' in 'the emotive department', but he did not consider this a form of insanity in the strict sense, rather it was one of three types of 'deviation from health in which mental phenomena predominate'- the other two being insanity and idiocy. ${ }^{22}$ It is important to note, too, that both Mayo and Davey associated brutality and moral perversion-and the emotions more generally - with the lower bodily appetites rather than the higher mental faculties. This is an apt illustration of how older philosophical and medical concepts were fused with the new sciences in this period. The language used to talk about human activity was ambiguous in this sense, with 'emotions' at times being used interchangeably with 'passions', at times to denote bodily 'appetites', and other times as an umbrella term for all mental activity that was considered to have a somatic basis, separate from the intellect.

This oscillation between old and new language was particularly evident in aetiological descriptions. Prichard's account of how a person would become affected by the melancholic subtype of monomania is a case in point:

An individual of melancholic temperament, who has long been under the influence of circumstances calculated to impair his health and call into play the morbid tendencies of his constitution, sustains some unexpected misfortune, or is subjected to causes of anxiety; he becomes dejected in spirits, desponds, broods over his feelings till all the prospects of life appear to him dark and comfortless. ${ }^{23}$

The idea of a 'melancholic temperament' gradually declined later in the century, but a belief in the predisposition to certain forms of mental disease was maintained by late Victorian physicians through narratives of heredity. In the first half of the century, however, the holistic language of temperament took precedence over a physiological aetiology emphasising cerebral morbid processes in descriptions of melancholia. This was even more prominent in Mayo's discussion of mental disease, where the language used to describe the different forms of insanity was explicitly 
humoural. Mayo deployed the simple tripartite division of mania, melancholia, and dementia, respectively associated with 'sanguine', 'bilious', and 'leucophlegmatic' temperament. Overall, however, Mayo devoted scant attention to melancholia, including only one case study of the disease in his textbook. ${ }^{24}$

Like Prichard, Davey did not find melancholia particularly useful as an independent disease category, suggesting that ' $[\mathrm{m}]$ any patients said to be suffering from melancholia labour, in point of fact, under mania; but, in these cases, the most prominent symptom is grief'. In other cases, melancholia was best understood as a form of moral insanity in the broad psychological meaning adopted by Prichard. ${ }^{25}$ A point upon which Davey clearly set himself apart from both Prichard and Mayo, however, was in regard to the internal explanation of mental disease, where he adopted a physiological perspective. As noted in Chapter 2, Davey based his theory of disordered emotion and ideation upon Billing's work, suggesting that the latter 'demonstrates that "the consequence of the brain or spinal cord becoming in a state of morbid sensibility is, that their healthy actions are deranged". In language similar to that used by Laycock in the previous chapter, whereby abstractly described psychological states could produce morbid physiological reactions in the brain, Davey concluded that "mental excitement", such as anger, grief, fear, etc., which are analogous to the direct irritation of the brain or spinal cord by a depressed fracture or spicula of bone' would, if carried on over time, result in a 'state of morbid sensibility of the nervous centres'. ${ }^{26}$

\section{'Depression' as a Symptom of Melancholia}

Davey's reference to a 'depressed fracture' as an analogy to describe a brain in a state of morbid sensibility manifesting in depressed mood illustrates the multivalence of 'depression' as an emotional state in this period. In the second half of the nineteenth century, depression was increasingly constituted as one of four defining criteria of melancholia (the other three being mental pain, suicidality, and religious delusions, all of which are considered in Chapter 5). While the Oxford English Dictionary dates 'depression' back at least to late fourteenth-century astronomy, ${ }^{27}$ the term grew in popularity as a descriptive word in the modern period, and was used throughout the nineteenth century to denote a range of events and conditions. How the term entered the vocabulary of psychological medicine is uncertain; it was at least in part derived from the language of 
internal medicine, where it was used to speak of the action of the heart. ${ }^{28}$ From the turn of the nineteenth century depression gained significant popularity as a term used to talk about a slump in economic markets, and its gloomy connotation in this context cannot be ignored. 'Depression of spirits' was sometimes used to describe a melancholy state of mind prior to the nineteenth century, but as such was conceptually different from the 'mental depression' often referred to in Victorian medico-psychological literature on melancholia.

As noted in the Introduction, the regular use of 'mental depression' to describe the general emotional state of the melancholic in the nineteenth century has led twentieth- and twenty-first-century scholars both in the human and natural sciences to attempt to equate melancholia with the condition commonly known as clinical depression or Major Depressive Disorder in the present. For nineteenth-century physicians, the term was applied in a way that suggested a much more literal meaning, that of something being 'pressed down'. In melancholia, the 'tone' of the mind was slackened and subdued. The mental depression was one in which the operations of the brain were dampened, lowered. This pressing down of the mind was often seen as mirrored in overall bodily function, with digestion, respiration, and movement significantly slower than normal in cases of severe melancholia. Towards the end of the century London physician Charles Mercier suggested that melancholia was characterised by a 'depression of spirits' with a corresponding deceleration of bodily functions:

We find, therefore, that in melancholia there is evidence of want of vigour in all the bodily processes. The hair grows but slowly, the nails seldom want cutting, the mouth is dry, the digestion is sluggish, the bowels are constipated, the pulse is feeble, the breathing is shallow, the muscles are flabby, the bodily activity is diminished. Together with these bodily manifestations goes a depression of spirits which varies in degree from a trifling want of buoyancy to the profoundest misery and despair. ${ }^{29}$

Victorian medical psychologists spoke of a 'depression of spirits', or an 'emotional' or 'mental' depression when describing melancholia, but the term was predominantly used as a way to describe the overall state of the melancholic mind, and as a way to contrast melancholia with mania-the opposite state of 'mental excitation'. In this way, depression was a helpful 
concept in the process creating boundaries of classification, but it was not used in place of melancholia, as a term denoting a specific disease.

\section{From Conolly to Sankey: Remaking Melancholia}

In 1846, British physician John Conolly gave a series of lectures at Hanwell asylum, where he held the position of medical superintendent prior to Sankey. Conolly is perhaps best known to posterity as a vocal champion of non-restraint (and, later, as Henry Maudsley's father-in-law). However, as a well-known and influential asylum physician Conolly was also an important source of knowledge about the diagnostics of mental disease for students and younger practitioners. His 'Clinical Lectures on the Principal Forms of Insanity' were subsequently published in The Lancet over several issues. Of the different types of madness addressed, Conolly awarded the most attention to melancholia, the discussion of which constituted three separate articles.

Conolly remained consistent with earlier works in that he did not classify melancholia as an independent disease category, suggesting instead that it was a 'variety of maniacal affection'. Nevertheless, he devoted a significant amount of space to melancholia, and argued that the nature of the symptoms exhibited warranted a separation of melancholia from other types of mania when explaining how to identify and diagnose it. Conolly's descriptive language displayed a mixture of old and new terminology that was characteristic of his generation. On the one hand, he suggested that melancholics were so predisposed because of their 'temperament' and that they could usually be identified according to certain characteristics of 'physical appearance' such as 'dark hair and eyes', 'long features', and 'a sallow complexion'. On the other hand, he incorporated modern medical language when describing the psychological features of the disease, emphasising the key symptom as 'depression of mind'. When discussing the aetiology of melancholia Conolly was chiefly concerned with 'moral' causes, these being 'grief,' 'care', 'distress', 'religious despondency', and 'conscientiousness in excess'. ${ }^{30}$ As with the symptomatology of the disease, there was evidence of biomedical language, though it remained unspecific. He suggested that while the illness could be triggered by such moral causes as mentioned above, more often melancholia 
creates its own distresses, coming on without adequate moral cause, some state of the brain being induced by which it is incapable of receiving pleasing impressions. This state is sometimes obviously connected with morbid actions or conditions of the liver, of the heart, of the intestinal canal, or of the uterus; but oftentimes the cause is wholly obscure; and the unexplained disposition to sadness hereditary. ${ }^{31}$

The framework for this description originates with physiological psychology, where both internal and external sensations could cause an automated emotional response. The idea that morbid action elsewhere in the body, for instance the uterus, could trigger a negative reaction in the brain leading to low mood echoes Laycock's discussion of nervous disorders in women a few years earlier. Conolly did not cite his influences, but he was writing at a time when the ideas of people like Laycock and Carpenter were gaining popularity among British physicians with an interest in mental disease. While not explicitly referring to reflexive action, Conolly drew upon this model to explain instances of melancholia apparently unmotivated by external causes. Going one step further, he also suggested that a mental depression of the mind triggered internally need not be linked to morbidity in a specific organ, but could be due to 'obscure' causes. Conolly did not elaborate further on what such causes might entail; however, his mention of heredity signalled a move towards a concept which would become important to all forms on insanity, as well as to criminality and vice, in the second half of the century. ${ }^{32}$ It is also important to note that his argument that the melancholic brain was 'incapable of receiving pleasing impressions' would be modified by later medical writers. As will be seen in subsequent chapters, the increasingly standardised description of melancholia that emerged in the second half of the century generally held that all impressions received by a morbidly sensitive brain, whether positive or negative, would produce feelings of displeasure.

Joseph Williams, a privately practising physician who primarily treated wealthy outpatients, was inspired by Conolly's work and largely followed his approach to the aetiology and classification of melancholia, bringing together traditional language on insanity with modern scientific research. Williams trained briefly at a number of hospitals around Europe and proceeded to bring together his observations and research in an 1852 textbook that situated him somewhere between early century alienists like Prichard and the new generation of medical psychologists who 
approached their profession and its objects of research from a strongly biomedical viewpoint. His view of mind and emotion was particularly coloured by traditional language. He perceived a division between on the one hand 'emotions', 'passions', 'propensities', and 'bodily appetites', and on the other the 'intellectual faculties' including the will. ${ }^{33}$ Contrary to the suggestions of some writers, he argued, 'judgment is always perverted in insanity, although in different degrees. ${ }^{34}$ Moreover, like Conolly Williams perceived a close link between insanity and 'temperament', suggesting that 'those with intensely black hair and eyes are of a nervous temperament and are more subject to melancholia'. ${ }^{55}$

Williams largely adhered to the classification of insanity put forward by the Metropolitan Lunacy Commission in the 1840s. As noted above, this system saw melancholia situated as a subcategory under 'partial insanity', alongside monomania and moral insanity. This nosology was maintained with the creation of the nationwide Lunacy Commission in 1845 , and would dominate for a few decades (though monomania and moral insanity were gradually phased out). It is not surprising, then, that a number of physicians writing in the $1850 \mathrm{~s}$ and 60 s adopted this system of classification, regardless of their aetiological approach to mental disease. Moreover, as discussed in Chapter 5, this gradual standardisation of diagnostic categories occurred despite resistance from the Medico-Psychological Association to formally adopting a standard nosology. ${ }^{36}$

One of the early presidents of the Association was Henry Monro (son of the famous Bethlem physician Thomas Monro), a consulting physician on mental disease at St. Luke's whose experience in diagnosing insanity led him to publish several works on the topic. He is of particular importance to the present story as his Remarks on Insanity (1851) was one of the earliest British works to fully embrace a view of mental disease firmly anchored in physiological psychology. Monro's adoption of a biomedical model for melancholia and other forms of insanity was rationalised through a now familiar type of analogy. If one believed that mental disease was a disorder of nervous function, one would, he argued, naturally seek to discover 'how far the mental excesses and deficiencies of insanity could be accounted for by the same rules that account for spasm and paralysis of motion'. ${ }^{37}$ While the abstract qualities of mind might differ from strictly somatic functions such as 'motion' and 'nutrition', Monro held that that since these distinct functions nonetheless used 
a common instrument, - namely, nervous matter, and as this mechanism is of the same nature, subject to the same infirmities, and intimately connected in its various parts both by sympathies and continuity, we must believe that, so far as the various phenomena presented through nervous instrumentality are really dependent on this similar mechanism, similar results are to be anticipated. ${ }^{38}$

Like Conolly, he also perceived a causal relationship between somatic and mental operations, whereby a disturbance in an organ elsewhere in the body could reflexively trigger a painful cerebral reaction. ${ }^{39}$ A healthy mind was one where a 'static condition of the nervous system' was maintained, and where a mental reaction would only occur when 'it is called forth into action by its own proper stimuli'. Conversely, a morbid condition 'is that wherein abnormal stimuli set in action and produce the same effects that proper stimuli should' ${ }^{40}$

Following from this, Monro put forward a five-point definition of 'the pathology of insanity' based on a psycho-physiological model of mind and brain. He suggested that mental disease constituted 'an affection consequent on depressed vitality', and that 'when the cerebral masses are suffering from this condition of depressed vitality, they lose that static equilibrium of the nervous energies which we call tone'. This muscle metaphor used by Monro to illustrate the state of healthy nervous and mental function became popular with the next generation of medical writers whose work is considered in subsequent chapters, and was deployed to suggest that the 'tone' of the brain was slackened or lost. ${ }^{41}$ The analogous relationship between the physical and the mental was then further reinforced by Monro through the suggestion of a reversal of the causal relationship in which 'coincidentally with this want of tone, manifested in the seat of the sensorial faculties, there exists very frequently in the insane a marked want of vitality and nervous tone in those parts of the system which are connected with physical life', such as the skin. ${ }^{42}$ In sum, then, somatic disturbances would often give rise to morbid mental reactions leading to or constituting insanity, a condition of lost equilibrium and 'tone' of the cerebral nervous tissue. When the tone of the mind and brain was diminished or lost this would subsequently often lead to an externally manifest loss of tone, such as of the skin or muscles.

When it came to diagnostics, Monro found distinct categories of mental disease less useful than a division of stages into 'acute', 'chronic', and 'imbecile', suggesting that any more detailed and precise distinction was difficult to maintain in a clinical setting. ${ }^{43}$ Nevertheless, he 
proceeded to divide insanity into a number of categories and subcategories. On the status of melancholia as an individual diagnostic category Monro largely followed the recommendations of the Lunacy Commission, including it under the heading 'partial insanity', suggesting that it could manifest without delusion of thought. The description he offered was heavily anchored in the new biomedical language. Melancholia was, he suggested, a condition in which there was a 'general and extreme prostration of all nervous and physical power'; in other words, a 'depression' of nervous power and consequently of mood. In this type of disorder,

the patient does not manifest any delusion until his lowness becomes excessive and more than ordinary, and then his extreme depression runs into terror and anxieties which have no real source; every effort is performed with morbid dread, even the least movement seems sufficient to raise anxious fears; sounds are listened to with anxiety, objects of sight cause an extremely morbid interest: this is a state, in short, of distressing sensibility, which only occasionally runs into real aberration of mind. ${ }^{44}$

Melancholia, then, was chiefly a disorder of affectivity, which in the more advanced stages could also manifest in delusion of thought. Later in the century physicians would generally distinguish more clearly between the non-delusional and delusional forms of the disease by referring to the former as simple melancholia. It would be argued by Henry Maudsley and others that the suffering tended to be greater in this form of the disease, as subjects were fully aware that their mental pain was unfounded and irrational. ${ }^{45}$

A model very similar to Monro's was presented a few years later by George Robinson, asylum physician and lecturer in mental disease at Newcastle. Robinson explained the mind-body relationship by perceiving the brain as the medium between the two, meaning that its health or illness was subject to both mental and physical disturbances. ${ }^{46}$ In other words, the brain could be excited by psychological factors-recall the 'mention' of water in Laycock's example of hydrophobia discussed in Chapter 2-as well as by known or unknown activity elsewhere in the body. Robinson was, however, quick to caution his peers against presumption and speculation, warning that 'the precise laws regulating in individual cases the production of the various forms of functional nervous disorder' were 'as yet very imperfectly known. ${ }^{47}$ However, there was, he argued, 'one law explanatory of a large and important group of nervous 
affections which must not be passed over in silence, namely, the law of reflex action'. From the basic sensation-motion reflex Robinson perceived two analogous laws; the first being

that the morbid impression produced by a source of irritation existing in a distant part of the body, may be transmitted by the incident nervous fibres to the spinal cord and brain, and thence reflected to various motor nerves, giving rise to convulsions and other results of disordered nervous action. ${ }^{48}$

Following from this, the second law was, he suggested, 'less capable of direct experimental demonstration', but no less central to understanding the emergence of mental disorders. According to this law, 'reflected morbid stimuli' would 'give rise to painful affections in parts far distant from the original seat of irritation, as for instance, in some forms of neuralgia, in sick headache from indigestion, \&c'. While having warned against careless conjecture, Robinson nevertheless ventured a third possible law derived from the sensory-motor reflex concept. This was the process ordinarily referred to as 'the association of ideas'. For what was this process, he asked, 'but a species of reflected feeling, which from the most trivial circumstances can call into existence, and evolve, an elaborate chain of thoughts and sentiments, apparently the most remote and unconnected?' 49

Just like sensation, then, emotion could travel as an automated reaction and trigger 'an elaborate chain of thoughts and sentiments'. In a similar fashion to the models offered by Griesinger and Laycock, this analogy described by Robinson largely erased any hierarchical separation between emotion as somatic and ideas and volition as cerebral. Rather, the functions of the mind were, according to Robinson, the result of operations of the brain, which in turn equally depended upon activity elsewhere in the body. A reflexive relationship existed between mind, body, and brain in conjunction, and between emotion and ideas as products of this relationship. It is easy to see how this framework allowed for a range of aetiological explanations for insanity, and specifically for a conceptualisation of disordered emotion as a form of mental disease.

It follows, then, that Robinson believed melancholia to arise from a number of factors, and that this disease did not necessarily entail delusion of thought and judgement: 'Some patients display merely lowness of spirits, with a distaste for the pleasures of life, and a total indifference to its concerns. These have no disorder of the understanding, or defect in 
the intellectual powers', while others 'derive their grief and despondency from some unreal misfortune which they imagine to have befallen them'. Robinson, too, deployed a nosology similar to the one sanctioned by the Lunacy Commission, which saw melancholia fall under the category 'partial insanity' together with monomania and moral insanity. However, he perceived a much more marked distinction between these three forms of disorder than many other contemporary writers. Taking the literal (and, following Esquirol, original) definition of monomania, he described it as a form of insanity where the patient's intellect was compromised only in relation to one 'particular topic', this frequently being the idea that 'they hold conversations with supernatural beings.' Moral insanity, on the other hand, was often free of delusion, but manifested in 'a total want of self-control, with an inordinate propensity to excesses of various kinds. ${ }^{50}$

As we have seen, mid-century medical writers were increasingly turning to physiology for language and concepts with which to explain mental disease. This shift was particularly apparent in the work of Daniel Noble, medical officer at a private lunacy facility in Manchester, where he also lectured in mental diseases at the Chatham Street School of Medicine. His Elements of Psychological Medicine (1853) acknowledged a significant intellectual debt to Carpenter's work, and appropriated much of the latter's framework for mental physiology. Noble based his theory of mental disease on a psycho-physiological framework of the mind and brain, in which ideas, emotions, and actions could arise reflexively, without external stimuli. ${ }^{51}$ However, he departed somewhat from Carpenter's model in designating the different mental faculties to their correct physical location. While Carpenter had assigned emotion to the 'the ganglia of the nerves of special sensation', 52 Noble suggested that it inhabited its own specific space separate from 'the sensibility of the five senses', namely in 'the Optic Thalami and Corpora Striata'. ${ }^{53}$ It was evident, Noble argued, from 'the speciality of emotional sensibility' that emotion must originate in 'proper nervous centres'. The reactive power of emotion was significant, he argued, and actions would 'often arrive immediately and exclusively from this inner sensibility'. ${ }^{54}$ It is not surprising, then, that Noble was unequivocal in suggesting the possibility of 'emotional disorder' in which there was 'no perversion of ideas'. However, Noble was equally firm in the view that he would 'never characterise such cases as insanity, so long as the reason evinced itself unimpaired. ${ }^{55}$ Where, then, did that leave melancholia? Here, Noble set himself apart 
from many of his peers in suggesting that cases of 'melancholic depression' of limited duration and where reason was left fully intact should not be considered pathological. ${ }^{56}$ Morbid melancholia, he argued, was a state characterised by 'a fixedness and permanence in the moral depression' in which 'the ideas' would 'sustain perversion'. However, in summing up the differences between non-pathological melancholy and melancholia, Noble's description of the latter resonated with contemporaneous views:

In melancholia, the circumstances are disproportionate to the result; and the ulterior development of the emotional state, becomes referable, very often, to classes of ideas that have no immediate relation with the primary facts occasioning the mental distress; the moral disposition, in other respects, is found to have undergone some notable change, not to be accounted for by ordinary influences; and, moreover, there are often physical signs of nervous irritability or cerebral disturbance. ${ }^{57}$

The view that melancholics tended to attribute an incorrect cause to their suffering would be cited repeatedly by medical writers later in the century. While twenty-first-century scholars have described melancholia in this period as 'sadness without cause', 58 this is a slight misconception of how Victorian physicians perceived it. They distinguished between external and internal causes - the former would usually be (wrongly) suggested by patients, whereas the latter could be correctly assigned by the medical psychologist.

As the works discussed above indicate, during the 1850s the landscape of British psychological medicine was rapidly growing fertile as an increasing number of physicians decided to turn their experience in the diagnosis and observation of mental disease into educational publications. One textbook would, however, tower over other contemporary literature on the topic. Appearing in several editions throughout the early second half of the century, Bucknill and Tuke's Manual of Psychological Medicine was one of the most widely circulated textbooks on insanity of the midVictorian period, and Tuke's equally impressive Dictionary ${ }^{59}$ published in the 1890s saw contributions from a range of Britain's most prominent medical psychologists. With the Manual, Tuke and Bucknill gave British physicians their most comprehensive textbook on insanity since Prichard's Treatise. Indeed, it was the authors' own explicit aim to replace this book with a more modern publication on the topic. ${ }^{60}$ They offered a wideranging survey of medical opinion on insanity from ancient times until 
the present, paying particular attention to recent works by home-grown physicians such as Conolly and Monro.

However, remarkably little space was devoted by the authors to the physiology and pathology of mental disease. The reason for this was alluded to by the cautious attitude displayed towards the promise and potential of recent empirical research. Despite what they perceived as great advances in internal medicine more generally, Tuke and Bucknill held fast to the view that the true functions of the brain and their correlation with mental phenomena were in all likelihood perpetually beyond the grasp of human knowledge. Following from this, they were highly critical of physicians who tried to attribute all mental disease to one particular type of disturbance of nervous function, such as 'exhaustion', 'irritation', or 'inflammation'. However, in a broad sense they agreed that all forms of insanity, being disorders of the mind, were also disorders of the brain, and 'that diseased conditions which affect the mental functions must have their seat in the grey matter of the cerebral convolutions'. ${ }^{61}$ Importantly, the authors did not perceive a division between higher and lower mental faculties, suggesting instead that the brain was the seat of emotion as well as of the intellect.

The model of emotion as a reflexive function of the brain prone to interact with ideas in a similarly involuntary manner formed the basis for Tuke and Bucknill's explanation of the mental suffering typical in melancholia. The despondency of melancholics tended to be at its worst in the early morning, they argued, and this could most likely be attributed to

the unwonted activity and force which attend all operations of the mind at this period. Every one must have observed the vividness with which suggestions occur to the mind, and ideas irresistibly succeed each other, when conscious, although involuntary cerebration is then first put in action. ${ }^{62}$

Like other authors at the time, they were of the opinion that melancholia could be present with or without delusion of thought and judgement. ${ }^{63}$ The authors largely adhered to the nosology endorsed by the Lunacy Commissioners; however, they suggested following Esquirol and Prichard that melancholia could in fact be seen as a type of monomania. However, later editions of Tuke and Bucknill's Manual would place stronger emphasis on a biomedical perspective, as well as on melancholia as a distinct disease entity. 
Continuing this trend, John Millar's Hints on Insanity (1861) reflected several contemporaneous developments, drawing together a physiological explanatory framework with a system of classification that gave prominence to melancholia, mania, and general paralysis. Millar's monograph also contained extensive helpful notes on how to fill out the medical certificates of insanity that were required for the admission of patients under the 1845 Lunacy Law. In regards to melancholia, Millar suggested that there was 'frequently no mental aberration detectable', reaffirming the view that the disease could manifest without delusion. ${ }^{64}$ For the most part, Millar's brief monograph consisted of disseminating existing views. However, his discussion of melancholia contained an observation that was at this time relatively peripheral in medico-psychological literature, but which would a mere two decades later be widely accepted as a medical fact, as will be seen in subsequent chapters. 'Every case of melancholia', Millar suggested, 'should be looked upon as having a suicidal tendency. ${ }^{\prime 65}$

As the works discussed in this chapter suggest, when William Sankey published his survey of current medical opinion on melancholia in 1863 something of a coherent approach was beginning to emerge. In published material there was growing agreement on the validity of a biomedical approach to mental health and disease, and the view of emotion as cerebral and subject to disorder was becoming widely accepted. While disagreement on the nosological status of melancholia prevailed, descriptions of the disease were becoming increasingly distinctive as well as comprehensive. When Sankey arrived at his own observations on this disease category, then, the model he offered was firmly anchored in biomedical language. Beginning by discussing the 'excitory-sensatory' and 'excitory-motory' action of the central nervous system, he arrived by analogy at a concept similar to that of Laycock's cerebral reflexion, suggesting that 'illusions' occurred through a mental process analogous to that which produced 'convulsions'. ${ }^{66}$ The cause of these 'illusions' (by which is taken to mean the mental or ideational correlate of a physical convulsion-essentially a convulsion of ideas) was 'an abnormal (state) in the nutritive changes of the nervous centres'. ${ }^{67}$ The physiological model suggested by Sankey to explain the emergence of disordered emotion was carried over into his description of melancholia as a diagnostic category. He described melancholia as 'a group of morbid phenomena or symptoms......characterised chiefly by depression of spirits'. Sankey went on to list various manifestations of morbid emotion displayed in 
melancholia, such as mental pain, fear, depression, despondency, selfishness, and suicidal intentions. ${ }^{68}$ In this way, Sankey and his contemporaries tried to solve the problem of how to wed a scientific, biomedical model of mental disease with the external manifestations of the patients they encountered by describing an increasing number of the 'symptoms' observed in a language compatible with the internal disease model.

\section{CONCLUSION}

Sankey's attempt to reconcile the new biomedical language of disordered emotion with the diagnostic picture of melancholia highlights a conundrum that would pursue medical psychologists throughout the rest of the century. At the same time, however, the language of physiology was making itself increasingly evident in the external symptomatology of melancholia. As this chapter has documented, psycho-physiology gave rise to a new language for descriptive psychopathology, where symptoms such as 'mental pain' and 'depression' were perceived as key features of melancholia. While these symptoms began their life in medical literature, physicians claimed with increasing regularity to observe them in melancholic asylum patients.

The argument that melancholia could present completely without delusion of thought or moral judgement was gradually assuming the status of medical fact at mid-century. Such a belief was in part facilitated by a model of the mind in which the emotions were able to interact and react with ideas. Some writers maintained a hierarchical separation between emotion and intellect, but allowing for the ability of these faculties to interact and react within a framework that nevertheless constituted emotion as chiefly psychological. For an increasing number of medical writers, however, emotion was perceived as cerebral. Moreover, for more strict materialists like Laycock all mental functions, being functions of the brain, were subject to involuntary reflexive action. One of the first medical psychologists and asylum physicians to develop a detailed and comprehensive monograph based on these ideas and devoted solely to the mind and its disorders was Henry Maudsley. His monumental The Physiology and Pathology of the Mind, first published in 1867, endeavoured to fully bring together existing physiological knowledge of mental operations and show how the pathology of insanity was not a separate scientific discipline, but merely an extension of physiology. Maudsley's first textbook was a 
work of medicine, but more than this it offered a comprehensive psychological framework for normal and pathological emotion, a framework which merged the languages of physiology, psychopathology, and evolutionary theory. Maudsley was strongly influenced by both Laycock and Carpenter, but also by the biological and increasingly academic research on mental disease that was coming out of the German states in the 1860s. In Germany, psychiatry became a concept, a trade, and an academic discipline earlier than in Britain, a development spearheaded by an ambitious doctor from Göttingen, Wilhem Griesinger. Griesinger developed a model of psychological reflex action at the same time as Laycock, and applied it to his aetiological work on mental disease. As will be seen in the next chapter, he wrote extensively on melancholia, and influenced a new generation of German psychiatrists whose work was strongly neurological in character.

\section{Notes}

1. William H.O. Sankey, "On Melancholia," Journal of Mental Science 9 (1863): 173-196.

2. In the article, Sankey discussed recent works by Tuke and Bucknill, Winslow, Griesinger, Neumann, Wachsmuth, Dagonet, Marcé, Morel, and Calmeil.

3. Sankey, "On Melancholia," 173.

4. Philippe Pinel, A Treatise on Insanity (Sheffield: W. Todd, 1806), esp. preface, 16-19, 242.

5. See also Thomas Dixon, "Emotion': The History of a Keyword in Crisis," Emotion Review 4 (2012): 338-344 and From Passions to Emotions: The Creation of a Secular Psychological Category (Cambridge: Cambridge University Press, 2003).

6. Forbes Winslow was the founder of the journal in 1848 and its chief editor for the next 16 years. See Michael Shepherd, "Psychiatric Journals and the Evolution of Psychological Medicine," Psychological Medicine 22 (1992): 18; Jonathan Andrews, "Winslow, Forbes Benignus (1810-1874)," Oxford Dictionary of National Biography (Oxford: Oxford University Press, 2004), http://www.oxforddnb.com/view/article/29752.

7. (editorial) "On British Lunatic Asylums," Journal of Psychological Medicine and Mental Pathology 3 (1850): 88.

8. John Hitchman, "The Pathology of Insanity: A Lecture, Delivered May 25th, 1850, in the Middlesex County Asylum, Hanwell," Journal of Psychological Medicine and Mental Pathology 3 (1850): 520. Emphasis in original. 
9. Hitchman, "The Pathology of Insanity," 510-511.

10. One area in particular where this occurred was that of biographical writing. For an engaging study of the role of melancholia and melancholy in the biographical works of British writers in the modern period, see Jane Darcy, Melancholy and Literary Biography, 1640-1816 (New York: Palgrave Macmillan, 2013). For melancholia and biography in European writing more generally, see Karin Johannisson, Melankoliska Rum: Om ångest, leda och sårbarbet $i$ forfluten tid och nutid (Stockholm: Bonniers, 2009).

11. James Cowles Prichard, A Treatise on Insanity and Other Disorders Affecting the Mind (London: Sherwood, Gilbert \& Piper, 1835), preface.

12. German E. Berrios, "Classic Text No. 37: J.C. Prichard and the Concept of Moral Insanity," History of Psychiatry 10, No. 37 (1999): 111-126; William F. Bynum, "Theory and Practice in British Psychiatry from J.C. Prichard (1786-1848) to Henry Maudsley (1835-1918)," in History of Psychiatry: Mental Illness and Its Treatments, Proceedings from the 4th International Symposium on the Comparative History of Medicine-East and West, ed. Teizo Ogawa (Osaka: Saikon, 1982); Hannah F. Augstein, "J.C. Prichard's Concept of Moral Insanity: A Medical Theory of the Corruption of Human Nature," Medical History 40, No. 3 (1996): 311-343.

13. Prichard, A Treatise on Insanity, 6.

14. Johann Christian Heinroth, Lehrbuch der Störungen des Seelenlebens oder der Seelenstörungen und ihre Behandlung (Leipzig: Vogel, 1818). Verwey has divided early German psychiatric writers into two camps-'somaticists' and 'psychicists'. However, the former must be distinguished from a later materialist tradition emerging with Wilhelm Griesinger's work in the 1840s (see Chapter 4). Somaticists such as Jacobi still adhered largely to a view of human nature, mind, and brain steeped in Romanticist Natürphilosophie and maintained a belief in an independent abstract soul. See Gerlof Verwey, Psychiatry in an Anthropological and Biomedical Context: Philosophical Presuppositions and Implications of German Psychiatry, 1820-1870 (Dordrecht: Kluwer, 1985), esp. 27-34.

15. According to one view, Esquirol tried (and failed) to locate 'suicide' in the brains of dead asylum patients. See Ian Marsh, Suicide: Foucault, History and Truth (Cambridge: Cambridge University Press, 2010), 117-122.

16. Prichard, A Treatise on Insanity, 246.

17. Prichard, A Treatise on Insanity, 26-27.

18. Prichard, A Treatise on Insanity, 27.

19. Cf. 'moral treatment', which was both 'moral' (in today's meaning of the word) and psychological. With the physician as a stern but affectionate father figure, moral treatment aimed to restore lunatics to their rational selves through a combination of kindness, discipline, and light 
employment. See e.g. Samuel Tuke, Description of the Retreat (York: W. Alexander, 1813), esp. pp. 131-136.

20. Davey, "Lectures on Insanity," 829.

21 . The word brutality as used here should be understood as being closer in meaning to its etymological origins than its twenty-first century usagei.e. as associated with 'brutes'.

22. Thomas Mayo, Elements of the Pathology of the Human Mind (London: John Murray, 1838), 148-149.

23. Prichard, A Treatise on Insanity, 28.

24. Mayo, Pathology of the Human Mind, 66, 111-113.

25. Davey, "Lectures on Insanity," 828-829.

26. Davey, "Lectures on Insanity," 831.

27. For instance: "And than is the depressioun of the pol antartik, pat is to seyn, than is the pol antartik by-nethe the Orisonte the same quantite of space.' Geoffrey Chaucer, A Treatise on the Astrolabe: Addressed to His Son Lowys (London: N. Trübner \& Co., 1872 [1391]). Reference derived from the $O E D$ entry on 'depression': http://www.oed.com/ (accessed 04/05/2013).

28. See Fay Bound Alberti, Matters of the Heart: History, Medicine, and Emotion (Oxford: Oxford University Press, 2010), for the shift from the heart to the brain as the centre of feeling, a shift that nevertheless saw the former's significance maintained as a metaphor.

29. Charles A. Mercier, Sanity and Insanity (London: Walter Scott, 1890), 337. See also e.g. Henry Maudsley, The Pathology of Mind, 4th ed. (London: Macmillan, 1879 \& 1895), 164; John C. Bucknill and Daniel Hack Tuke, A Manual of Psychological Medicine, 4th ed. (London: John Churchill, 1879), 220-221; George Savage, Insanity and Allied Neuroses: Practical and Clinical (London: Cassell, 1884), 152-154.

30. John Conolly, "Clinical Lectures on the Principal Forms of Insanity, Lecture VII," The Lancet (January 3, 1846): 1.

31. Conolly, "Clinical Lectures," 1.

32. See e.g. Henry Maudsley, Responsibility in Mental Disease (London: Henry S. King, 1874).

33. Joseph Williams, Insanity: Its Causes, Prevention, and Cure, 2nd ed. (London: John Churchill, 1852), 4-5.

34. Williams, Insanity, 7.

35. Williams, Insanity, 39.

36. The Medico-Psychological Association, which originated in 1841 as the Association of Medical Officers of Asylums and Hospitals for the Insane, was the main forum for discussion of clinical, administrative, and theoretical questions for British physicians working in the field of mental disease. See Chapter 5. 
37. Henry Monro, Remarks on Insanity: Its Nature and Treatment (London: John Churchill, 1851), vii.

38. Monro, Remarks on Insanity, vii. Emphasis in original.

39. Monro, Remarks on Insanity, 5.

40. Monro, Remarks on Insanity, 10.

41. Monro, Remarks on Insanity, 12.

42. Monro, Remarks on Insanity, 14.

43. Monro, Remarks on Insanity, 2.

44. Monro, Remarks on Insanity, 27.

45. See Chapter 5.

46. George Robinson, On the Prevention and Treatment of Mental Disorders (London: Longman, 1859), 20-23; 43.

47. Robinson, Prevention and Treatment, 44-45.

48. Robinson, Prevention and Treatment, 44.

49. Robinson, Prevention and Treatment, 44-45. Emphasis in original.

50. Robinson, Prevention and Treatment, 53-54.

51. Noble adopted Carpenter's concept of ideo-motor action, but suggested that such activity could perhaps be more aptly termed 'ideo-dynamic'. Daniel Noble, Elements of Psychological Medicine: An Introduction to the Practical Study of Insanity (London: John Churchill, 1853), 69-71.

52. See Chapter 1.

53. Noble, Psychological Medicine, 72-74. Here, Noble departed from a view endorsed by a number of mid-century scientists, who perceived these two regions as constituting the centres of movement and sensation. Robert M. Young, Mind, Brain and Adaptation in the Nineteenth Century: Cerebral Localization and Its Biological Context from Gall to Ferrier (New York: Oxford University Press, 1990), 111-113. In the last quarter of the century, experimental physiologists would more firmly suggest their central role in bodily movement. Galvanic experiments on dogs indicated that after removal of the hemispheres, motor action was still possible following direct stimulation if the optic thalami and corporal striata were left intact. See e.g. David Ferrier, The Functions of the Brain (New York: G.P. Putnam \& Sons, 1876), 214.

54. Noble, Psychological Medicine, 76.

55. Noble, Psychological Medicine, 180-181.

56. Cf. Maudsley on simple melancholia, Chapter 5.

57. Noble, Psychological Medicine, 215-216.

58. Allan V. Horwitz and Jerome C. Wakefield, The Loss of Sadness: How Psychiatry Transformed Normal Sorrow into Depressive Disorder (Oxford: Oxford University Press, 2007), 66-71.

59. Daniel Hack Tuke, ed., A Dictionary of Psychological Medicine (London: J.A. Churchill, 1892). 
60. John Charles Bucknill and Daniel Hack Tuke, A Manual of Psychological Medicine (London: J.A. Churchill, 1858), preface.

61. Bucknill and Tuke, A Manual of Psychological Medicine, 389. Emphasis in original.

62. Bucknill and Tuke, A Manual of Psychological Medicine, 157.

63. Bucknill and Tuke, A Manual of Psychological Medicine, 157-159.

64. John Millar, Hints on Insanity (London: Henry Renshaw, 1861), 22.

65. Millar, Hints on Insanity, 23.

66. Sankey, “On Melancholia," 193-194.

67. Sankey, "On Melancholia," 194.

68. Sankey, “On Melancholia,” 179.

Open Access This chapter is licensed under the terms of the Creative Commons Attribution 4.0 International License (http://creativecommons.org/licenses/ by $/ 4.0 /)$, which permits use, sharing, adaptation, distribution and reproduction in any medium or format, as long as you give appropriate credit to the original author(s) and the source, provide a link to the Creative Commons license and indicate if changes were made.

The images or other third party material in this chapter are included in the chapter's Creative Commons license, unless indicated otherwise in a credit line to the material. If material is not included in the chapter's Creative Commons license and your intended use is not permitted by statutory regulation or exceeds the permitted use, you will need to obtain permission directly from the copyright holder.

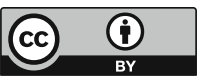

